\title{
Religião e educação: um desafio para o trabalho docente - entrevista com Françoise Lantheaume ${ }^{1}$
}

\author{
Maria da Graça Jacintho Setton² \\ Gabriela Abuhab Valente ${ }^{2}$
}

\section{Resumo}

O objetivo desta entrevista é apresentar o trabalho e a reflexão da Professora Françoise Lantheaume, diretora - desde 2012 - do Laboratório Educação, Cultura e Política (ECP) da Universidade Lumière Lyon 2, França. Françoise Lantheaume vem estreitando laços com a Faculdade de Educação da USP em função de uma pesquisa de caráter internacional acerca de aspectos relativos à discriminação, ao racismo e à religião dentro da escola. Intitulada Religions, discriminations et racisme en milieu scolaire (ReDISCO), a investigação deverá estender-se até 2020 e conta com a colaboração de um consórcio de laboratórios franceses e estrangeiros, entre os quais se inclui, no Brasil, a Universidade de São Paulo, a Universidade Federal de Pernambuco, a Universidade Federal do Paraná, a Universidade Federal do Amazonas e a Pontifícia Universidade Católica do Rio de Janeiro. Além disso, as publicações e a participação da entrevistada em um conjunto de palestras vêm contribuindo para a ampliação da reflexão acerca de um tema candente da realidade contemporânea, auxiliando na socialização de embates com a comunidade escolar. Mais especificamente, o tema da religião na escola, laicidade e discriminação, assim como o sofrimento e o mal-estar dos professores nos ambientes escolares vêm sendo objetos de estudo do laboratório coordenado por Françoise Lantheaume. Trata-se, pois, de assuntos que mobilizam preocupações nacionais e internacionais, os quais a revista Educação e Pesquisa, por tradição, vem debatendo.

\section{Palavras-chave}

Educação - Religião - Escola - Professores.

1- Tradução: Gabriela Abuhab Valente. Revisão técnica: Maria da Graça Jacintho Setton.

2- Faculdade de Educação, Universidade de São Paulo, São Paulo, SP, Brasil. Contatos: gracaset@usp.br; gabriela.abuhab.valente@gmail.com 


\section{Religion and education: a challenge to teachers' work - interview with Françoise Lantheaume}

\section{Abstract}

The aim of this interview is to present the work and thoughts of Professor Françoise Lantheaume, who has been since 2012 the director of the Laboratory on Education, Culture, and Politics (ECP) at the University Lumiére Lyon, France. Françoise Lantheaume has been creating closer ties with School of Education at USP as a result of her international research into discrimination, racism, and religion in schools. Such study, named "Religions, discriminations et racisme en milieu scolaire (ReDISCO)", will be carried out until 2020. It relies on collaboration between a group of French and foreign laboratories. In Brazil, it includes the University of Sao Paulo, the Federal University of Pernambuco, the Federal University of Paraná, the Federal University of Amazonas, and the Pontifical Catholic University of Rio de Janeiro. The interviewee's publications and her involvement in a set of academic conferences reveal her contributions and amplify the debate about burning contemporary issues, especially those occurring in the school communities. Specifically, the issue of religion in the school, laity and discrimination, as well as the teachers' suffering and the malaise in the school environment have been the objects of study by the laboratory headed by Françoise Lantheaume. These are, therefore, topics that mobilize both national and international concerns, which the journal Educação e Pesquisa have traditionally been discussing.

\section{Keywords}

Education - Religion - School - Teachers.

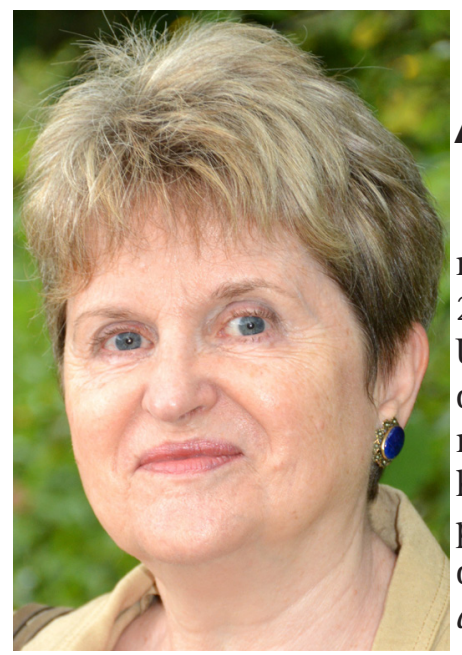

\section{Apresentação}

0 objetivo desta entrevista é apresentar o trabalho e a reflexão da Professora Françoise Lantheaume, diretora, desde 2012, do Laboratório Educação, Cultura e Política (ECP), da Universidade Lumière Lyon 2, França. Mme Lantheaume dirige pesquisas na área das Ciências da Educação e, mais especificamente, na Sociologia da Educação, tem habilitação como Professora Universitária ${ }^{3}$, título concedido pela Universidade Lumière Lyon 2. Em 2002, defendeu seu doutorado na mesma instituição, com o título L'enseignement de l'histoire de la colonisation et de la décolonisation de

Fonte: Arquivos da entrevistada.

3- 0 que corresponde, no Brasil, ao título de Professor Livre docente. 
l'Algérie depuis les années trente: état-nation, identité nationale, critique et valeurs. Essai de sociologie du curriculum. Françoise Lantheaume é também membro titular de vários conselhos e comissões universitárias francesas, demonstrando seu engajamento político administrativo na academia.

Sempre trabalhando em equipe interdisciplinar, Mme Lantheaume vem se ocupando em investigar a sociologia e a história do currículo, mais especificamente, o tratamento dado nas reformas curriculares acerca da diversidade cultural nas escolas e o conteúdo acerca da pluralidade e da diversidade das memórias históricas antagônicas, isto é, a natureza plural de normas constitutivas da nova ordem mundial. Ademais, desenvolve discussões a respeito da sociologia das organizações, o funcionamento dos estabelecimentos escolares e os desafios da profissão docente, oferecendo um material rico para o diálogo entre pesquisadores brasileiros e franceses.

A referida professora vem estreitando laços com a FE-USP em função do convite que recebemos para participar de uma pesquisa de caráter internacional acerca de aspectos relativos à discriminação, ao racismo e à religião dentro da escola. Intitulada Religions, discriminations et racisme en milieu scolaire (ReDISCO), a pesquisa conta com o apoio do Instituto Superior de Religiões e Laicidade (ISERL) da Université Lumière Lyon 2, órgão acadêmico que reúne grupos de estudos de diferentes países. Vale salientar que o engajamento acima relatado logrou a possibilidade de um convênio de dupla titulação para alunos de doutorado entre a Universidade de São Paulo e a Universidade Lumière Lyon 2 - França.

Desde 2015, participando das reuniões de seu grupo de pesquisa, pesquisadores brasileiros, notadamente as responsáveis por esta entrevista, vêm desenvolvendo discussões comparativas acerca da atividade docente entre países como Suiça, Canadá e França. Além de internacional, a equipe de pesquisa Religião, discriminação e racismo no espaço escolar é pluridisciplinar, mobilizando campos científicos como ciências da educação, sociologia, didática, história, linguística, psicologia e filosofia. Ela é também pluricategórica, ou seja, conta com pesquisadores com diferentes experiências, de professores universitários a estudantes em nível de pós-graduação, passando por professores da educação básica (professores associados).

0 objetivo da pesquisa é construir um quadro interpretativo das condutas de professores/as e funcionários frente a situações escolares que envolvam questões religiosas, de discriminação e de racismo. Dessa forma, buscam-se conhecer referências, recursos, lógicas de ação e necessidades para o desenvolvimento da atividade docente.

Inspirado em uma metodologia etnográfica, o estudo com funcionários da educação (professores, diretores, conselheiros educativos, assistentes pedagógicos etc.) propõe-se a responder as seguintes questões: Como eles agem? Quais recursos (humanos, dispositivos, argumentos ou outros) mobilizam em situações em que as questões da religião, da discriminação e do racismo são trazidas para o contexto escolar? Quais são as lógicas de ação e os princípios de justiça utilizado por esses atores em situação profissional? Como eles interpretam as expressões religiosas, as manifestações de discriminação e de racismo? Entre trabalho prescrito e trabalho real, quais ajustes são feitos pelos professores para lidar com injunções normativas? 
Tendo a sociologia pragmática (NACHI, 2012) como um aporte teórico, dentre as hipóteses de pesquisa destacam-se: 1) a existência de uma recomposição do modelo republicano de escola, ou seja, se anteriormente a representação de uma escola justa seria uma escola pautada em uma lógica cívica, hoje, a escola sofre influências de uma lógica liberal; 2) as ações docentes privilegiariam o contexto local e as dificuldades individuais dos alunos em detrimento das prescrições oficiais; e 3) as dificuldades encontradas pelos docentes, no que concerne à temática, desfavorecem o trabalho coletivo.

A pesquisa teve início em 2015 e seu término está previsto para 2020. Durante os dois primeiros anos, ocorreram encontros entre os pesquisadores a cada três meses, dedicados não apenas ao compartilhamento de resultados, mas também ao aprofundamento teórico. Dessa forma, as reuniões contavam com a participação de palestrantes renomados nas áreas de sociologia, educação e história.

0 ano letivo de 2017 foi concluído com a I Jornada de Estudos REDISC0, no dia 17 de outubro, cujo objetivo foi o de apresentar para a comunidade alguns resultados da pesquisa no que concerne ao Ensino Fundamental II. A jornada de estudo contou com um número importante de participantes (cerca de 200) entre professores, estudantes, pesquisadores e autoridades públicas.

Durante o evento, os membros da pesquisa puderam expor resultados preliminares a partir da análise de 316 entrevistas realizadas em 37 escolas públicas de cinco regiões da França. Após a apresentação da pesquisa e de seu percurso metodológico, o debate organizou-se a partir dos seguintes temas: efeitos do território, efeito da profissão e das disciplinas ensinadas, situações de trabalho, recursos e necessidades de formação e, por fim, abordagem internacional.

Alguns dos resultados merecem destaque. Os docentes e funcionários, ao tratar dos temas de religião, discriminação e racismo, utilizam o vocabulário legitimado por políticas públicas, embora os conceitos tenham pouca consistência e representem categorias fluidas. Em seguida, é possível afirmar que a organização do trabalho é um recurso utilizado pelos docentes para responder às dificuldades profissionais, bem como a trajetória pessoal e profissional dos docentes.

Ademais, o religioso no espaço escolar é interpretado pelos professores enquanto uma fonte de curiosidade e de aprendizagem dos alunos, que pode se apresentar de forma escolar (cultura religiosa) ou contraescolar (provocação). Contudo, a religião é utilizada pelos alunos de forma instrumentalizada, como uma maneira de constituir grupos dentro do espaço escolar na intenção de ocupar um espaço onde não têm poder.

Por fim, as análises revelaram que a função e a ética profissional estão ligadas. Isso indica uma boa vontade dos professores na vivência de situações cotidianas, cuja principal preocupação é a aprendizagem dos estudantes. Assim, temas como religião, discriminação e racismo acabam sendo relativizados em prol da escolarização dos alunos. Sendo, assim, raro o espaço para discussão de tais assuntos, de modo que a resolução desse tipo de conflito tende a ser individualizada.

A partir do ano de 2018, a pesquisa passa a abordar professores e funcionários do Ensino Médio. Além de fazer uma comparação com os docentes do Ensino Fundamental 
II, busca-se dar conta das especificidades dessa etapa da educação e das singularidades relativas à idade dos adolescentes.

No que tange ao interesse internacional, os resultados da pesquisa em andamento podem contribuir para o desafio sociológico, político, educacional e jurídico presente nos diferentes países, no que diz respeito à articulação entre identidades privadas e políticas públicas, a fim de preservar o espaço de cidadania comum e a capacidade de viver em sociedade.

Assim, o tema da religião na escola, racismo e discriminação, bem como o sofrimento e o mal-estar causados pela/na atividade docente nos ambientes escolares vêm sendo objetos de estudos da coordenadora da pesquisa REDISCO, Françoise Lantheaume. Ademais, as publicações e a participação da entrevistada em um conjunto de palestras acerca do tema em tela vêm contribuindo para a ampliação da reflexão a respeito de um tema candente da realidade contemporânea, auxiliando na socialização de embates com a comunidade escolar. Trata-se, pois, de assuntos que mobilizam preocupações nacionais e internacionais, tópicos entre os quais a revista Educação e Pesquisa, como tradição, vem debatendo.

\section{Referências}

DEBARBIEUX, Éric. Violence à l'école: un défi mondial? Paris: Armand Colin, 2006.

NACHI, Mohammed. Introduction à la sociologie pragmatique. Paris: Armand Colin, 2012. 


\section{Entrevista}

Eu gostaria, primeiramente, de agradecer a sua acolhida a esta entrevista. Desde algum tempo o seu objeto de pesquisa tem chamado atenção do público brasileiro, sobretudo no que diz respeito ao sofrimento e à atividade de ensinar. Recentemente, a senhora organizou, em 2015, uma pesquisa internacional acerca das questões religiosas, de discriminação e do racismo no espaço escolar (REDISCO). Nesse sentido, seria interessante se a senhora pudesse esclarecer-nos os objetivos de pesquisa. Ou seja, qual seria o seu ponto de partida, quais são os principais objetivos?

Como ponto de partida existe uma constatação e questões. A constatação é a de que o pertencimento religioso dos alunos e de seus pais se expressam de diversas formas no seio da escola e constitui um tema do debate público na França. É um fenômeno recente nas escolas francesas regidas por uma laicidade que deixa ou limita as crenças pessoais à porta da escola. As mídias, voluntariamente, dão uma visão dramática desses eventos atuais na escola, associados a um integrismo religioso intolerante. Assim, os professores não mais poderiam, segundo alguns textos midiáticos, ensinar os conteúdos do programa prescrito, pois alunos e pais - principalmente muçulmanos - impediriam que se trate da história de sua religião, do ensino da reprodução humana, da teoria da evolução ou da participação em atividades esportivas. Testemunhos de professores evocam as consequências negativas da afirmação das crenças religiosas dos alunos e de seus pais em seu trabalho. Esta é então uma questão viva que concerne os conteúdos de ensino, as práticas pedagógicas e as relações entre escola e família.

Os professores franceses, refletindo a imagem da população francesa, são majoritariamente não crentes ou agnósticos e foram formados em uma perspectiva de neutralidade laica: eles não devem manifestar suas crenças ou não-crenças e devem assegurar o respeito à liberdade de consciência dos alunos. Sua formação acerca das questões religiosas é frágil (com exceção dos professores de história e filosofia) tanto por conta da habitual ausência de cultura religiosa familiar quanto pela formação inicial e contínua que, até o período recente, ignorava a discussão religiosa. Poderíamos pensar que a socialização primária e secundária desses professores não os prepara para enfrentar facilmente a emergência de questões religiosas no espaço escolar. Além disso, as diversas manifestações relacionadas à situação geopolítica de guerras e do terrorismo podem reforçar certa timidez e insegurança desses profissionais.

Os professores não estão preparados para agir face aos fenômenos de discriminação, alguns ligados ao pertencimento religioso. A sensibilização para a discriminação é bastante recente e focalizada no bullying ${ }^{4}$ entre alunos, o que foi assunto de uma campanha institucional importante nestes últimos anos. 0 racismo é uma preocupação compartilhada pela imensa maioria dos professores que o combate há muitos anos em nome dos valores humanistas e do princípio da igualdade que estruturam a escola pública francesa desde sua origem. As competências e a atenção dos professores são variáveis acerca de todos esses assuntos.

4- Nota da tradutora: No original harecelment, perseguição ou intimidação. A academia francesa não se apropriou do termo americano bullying (DEBARBIEUX, 2006), como fez a brasileira. 
Nesse contexto, os objetivos da nossa pesquisa são os de verificar se a escola francesa é ameaçada pela irrupção de questões ou de reivindicações religiosas e se os professores são efetivamente desprovidos de recursos, como frequentemente afirma a mídia, mas também alguns intelectuais e políticos. Para isso, nós interessamo-nos pelas situações de trabalho e não pelas opiniões ou representações dos professores: como os professores agem concretamente quando as religiões, discriminações e racismo se apresentam na sala de aula, no estabelecimento escolar? Quais recursos eles mobilizam e quais estratégias eles utilizam? Como, eventualmente, isso afeta suas práticas pedagógicas, sua didática? Como eles justificam suas escolhas? Quais demandas (formação, instrumentos pedagógicos, organização etc.) eles apresentam que poderiam favorecer uma prática mais satisfatória, segundo suas próprias opiniões?

Nós privilegiamos uma abordagem pluridisciplinar para perceber as diferentes dimensões dessas questões (sociologia, didática, história, psicologia) e uma pesquisa qualitativa de tipo etnográfica para abordar sua complexidade.

\section{Qual é a justificativa para propor pesquisas internacionais?}

Pesquisas anteriores mostraram-me o interesse pela abordagem internacional que permite uma descentralização com relação aos hábitos de pensamento nacional, revelam alguns aspectos inéditos de nosso próprio espaço e informam-nos sobre a situação dos outros países. As trocas entre pesquisadores de países diferentes, com maneiras diferentes de interrogar um mesmo fenômeno social, são igualmente muito ricas, estimulam a abertura de espírito e impõem ainda mais o rigor.

A propósito do tema das religiões na escola, o interesse é maior pelo fato de que a relação das populações com a religião é bastante variável nos quatro países envolvidos na pesquisa. E o lugar da religião no sistema educativo é defınido diferentemente ao longo da história, em cada um dos contextos. Assim, é interessante comparar situações de trabalho dos professores envolvendo a religião, os recursos que eles mobilizam, suas estratégias e necessidades, assim como seus argumentos para compreender os princípios políticos que orientam suas escolhas, além dos efeitos da socialização profissional ou do ambiente de trabalho. Por último, como os professores constroem um mundo comum, indo além da diversidade dos alunos e das famílias.

No seu percurso de pesquisa, nós podemos perceber uma preocupação com o trabalho dos professores, sua profissionalização, mas, sobretudo, sua atividade real. Por que trabalhar isso? Qual é o método mais eficaz para abordar essa questão? Como essa dimensão do trabalho do professor é abordada na pesquisa REDISCO?

Meu interesse pelo trabalho docente estava ligado ao sentimento que ele seria conhecido apenas pela experiência que todos têm da escola e dos lugares comuns midiatizados acerca dessa profissão. Eu pude inspirar-me nos avançados estudos da sociologia do trabalho e das ciências do trabalho que se preocupam com o real do trabalho buscando apoio na ergonomia, que distingue o trabalho real do trabalho prescrito. Dessa forma, eu centrei a minha abordagem nas formas de fazer (gestos profissionais), nas 
relações profissionais, nas interações com o ambiente de trabalho e nas justificações das ações dadas pelos professores.

Eu compartilho a ideia, ainda minoritária, segunda a qual o trabalho é uma atividade política em que a democracia está presente, pois as questões de interesse geral estão no coração da atividade docente. Contudo, os professores estão em interação com outros atores que querem também ter sua palavra ouvida sobre as escolhas educativas que são feitas. Seguindo as contribuições da sociologia pragmática (BOLTANSKI; THEVENOT, 1991), que é uma sociologia da justificação, eu trabalho sobre as provas vividas pelos professores e sua forma de enfrentá-las no cotidiano. As provas são a ocasião do surgimento de controvérsias, da necessidade de justificação e de ascender à generalidade em direção aos princípios superiores. A maneira encontrada para superar uma prova permite o acesso ao conhecimento de hierarquias implícitas.

A noção de prova está aqui sendo entendida também no sentido colocado por Danilo Martuccelli. Prestando atenção aos argumentos, às lógicas de ação, à forma pela qual os atores se ligam aos princípios superiores de ordem política (igualdade, liberdade etc.) novos conhecimentos puderam ser produzidos sobre o trabalho docente e sobre a maneira pela qual os professores empregam, de forma situada, as injunções oficiais. Para isso, a sociologia da tradução derivada da sociologia das ciências (com os trabalhos de Callon, Latour, Akrich etc.) me forneceu igualmente instrumentos intelectuais preciosos que, pela primeira vez na França, eu apliquei ao espaço escolar.

Um método eficaz para acessar essas dimensões é a pesquisa de tipo etnográfica, associada à uma análise de corpus e até de um questionário, pois ela permite estudar o trabalho docente de forma situada e não somente fora de seu ambiente de trabalho. Além disso, a amplitude da pesquisa dá a possibilidade de fazer uma leitura transversal de monografias (37 colégios na França, 316 entrevistas, observações) com o objetivo de ligar o quantitativo e o qualitativo. É isso que nós praticamos na pesquisa REDISCO.

\section{Quais são as relações que a senhora estabelece entre educação, religião e cultura?}

Essas relações são historicamente e socialmente construídas. A educação é uma forma de transmitir a cultura e essa é, mais ou menos, dependendo dos períodos e lugares, nutrida de fenômenos religiosos. As escolhas feitas pela nação com relação ao peso acordado à religião na escola e a forma como os modos de socialização são mais ou menos clivados entre cultura vernácula e cultura erudita pelo meio da escola sublinham uma dimensão contextual decisiva na forma de considerar a relação entre educação, cultura, política. Na França, um projeto universalista concebido pela religião, ao mesmo tempo político e intelectual, tem historicamente sustentado a construção de saberes acadêmicos contra as crenças religiosas e, às vezes, contra a instituição que elas representam, a igreja católica.

Essa epistemologia dos conhecimentos acadêmicos encontra-se na escola que, por sua parte, conheceu uma laicização progressiva desde o fim do século XIX. Esse movimento tem sido muito conflituoso e alimentou uma desconfiança no seio da escola pública a respeito das religiões consideradas como perigosas por conta do poder temporal que elas reivindicam. No entanto, a escola francesa foi também construída sobre um 
modelo liberal, preocupado com a liberdade individual e de consciência de cada um. Suas características sócio-históricas forjam as características da relação entre educação, cultura e religião na França, que fazem, por exemplo, que a religião seja estudada em história, em educação cívica e moral e em filosofia como um objeto de saber, um fato histórico, cultural, não sob um ângulo da espiritualidade, nem como uma experiência compartilhada. No Brasil é diferente. Daí o interesse de uma abordagem comparativa para perceber os efeitos das construções sociais e os modos de socialização específicos.

De que modo a senhora vê a atual influência da religião no mundo e na França? Como a sociologia pragmática pode nos ajudar a trabalhar esse assunto?

Alguns afirmam que nós assistimos ao retorno do religioso, outros sublinham o fato de que é um recurso que durante um período de cerca de um século foi relativamente ignorado, mas que está sendo novamente mobilizado, redescoberto, por vezes, como meio de obter bens, reconhecimento, uma resposta às questões existenciais que o mundo moderno, mundializado e em crise não fornece mais.

A sociologia pragmática pode ajudar a compreender o fenômeno a partir da análise de argumentos que são utilizados em meio a controvérsias, a partir de questionamentos: como a religião é mobilizada pelos atores? Qual sentido que ela tem? Quais provas, tensões, acordos ou eventuais hibridações de lógicas ela produz? 0 que há de novo? Qual nova ordem do mundo se constrói em decorrência do que é produzido?

Percurso intelectual - Quais são os autores ou escolas de pensamento que lhe inspiram no que concerne à sociologia das profissões na França?

De forma geral, nos anos 1980, os trabalhos interacionistas foram difundidos na França e a influência de Everett Cherrington Hughes; Anselm Leonard Strauss; Howard Saul Becker e Erving Goffman são sensiveis na pesquisa sociológica francesa acerca das profissões que, dessa forma, se afastou de uma abordagem funcionalista. Após os trabalhos de Claude Dubar (2005), que atualizou o processo de socialização profissional, sobretudo dos professores, muitos pesquisadores em ciências da educação desenvolveram um corpus de conhecimentos importante acerca do trabalho de formadores e professores. Eu penso, por exemplo, nos trabalhos de Richard Wittorski ou de Anne Jorro. Podemos também citar sociólogos (alguns trabalham também em ciências da educação), como Patricia Remoussenard; Pierre Périer; Jérôme Deauvieau; Anne Barrère; Patrick Rayou, que exploram as evoluções do trabalho docente e de sua profissão. A tendência atual é de não separar a atividade docente da atividade dos alunos para compreender as aprendizagens e os modos de socialização produzidos pelo ensino. Daí decorre a ideia de desenvolver uma sóciodidática (nos termos de Rayou e Sansevy), o que tem conduzido sociólogos e pesquisadores da didática a trabalhar em conjunto.

Pessoalmente, os trabalhos que abordam o tema em outras profissões, para além dos docentes, como as pesquisas de Florent Champy acerca das relações profissionais ou de Michel Lallement a respeito das transformações do trabalho e a comparação internacional, 
inspiraram-me do mesmo modo que os estudos de Andrew Abbott que chamam atenção para as concorrências entre os grupos profissionais.

Quais são os autores que, na sua opinião, são os mais importantes no que diz respeito à sociologia dos sofrimentos na atividade docente?

$\mathrm{Na}$ verdade, existem poucos trabalhos na sociologia a respeito desse tema, para além daquele que eu coordenei com Christophe Hélou (2008). Os sociólogos que estudam os sofrimentos vividos no trabalho pesquisam outras profissões (educador especializado, enfermeiras, obreiros etc.). Com relação aos professores, as abordagens são mais psicológicas e estudam o estresse, o burn out, ou salientam a psicodinâmica do trabalho desenvolvida por Christophe Dejours ou a clínica da atividade criada por Yves Clot.

A senhora poderia explicar as pequenas, mas expressivas, transformações ocorridas em seus objetos de pesquisa recentemente? Formada em história, a senhora acabou trabalhando primeiramente no campo da sociologia do currículo, depois com o sofrimento dos professores e, mais recentemente, com as práticas de discriminação na França.

Minha dupla formação, em história e em sociologia da educação, conduz-me a nunca ocultar a dimensão histórica dos fenômenos sociológicos que eu estudo e a preferir os métodos de pesquisa que me permitam levar em conta a temporalidade. Isso está presente em todo meu trabalho, como a preocupação de articular a escala macrossocial das políticas públicas (reformas, definições de programas de ensino, por exemplo) e microssocial (a sala de aula, os gestos profissionais, as interações, os modos de socialização).

Que seja acerca da construção de um currículo e de sua aplicação na ocasião de um tratamento das questões vivas ou de reformas $(2004,2008)$, do sofrimento no trabalho (2008), da forma pela qual os alunos contam a história nacional (2016) ou da questão das religiões e discriminações na escola, a questão comum é a definição de um mundo comum: quais são as tensões, conflitos, contradições do mundo profissional dos professores e como ele se sustenta apesar de todas transformações? Como ele se recompõe? Mobilizando quais recursos? Qual novo sentido é dado às transformações nas quais os professores são os atores envolvidos?

Sobre a profissão docente - Existe ainda uma crise de adaptação da profissão docente? Por quê? De que modo a senhora compreende a mudança da profissão?

A crise de adaptação que Christophe Hélou e eu identificamos no início do século XX (nossa pesquisa data de 2000/2002) ainda perdura. 0 sistema educativo francês sofre os efeitos cruzados da massificação, da diversificação do público escolar por conta do aumento de migrações, por um lado, e de políticas públicas cada vez mais liberais e desreguladoras, tendo o enfraquecimento do Estado como algo indispensável para o sucesso econômico e colocando o indivíduo como centro de todas as atenções, por outro. Essa evolução não é linear e tem intensidades diferentes segundo os períodos, mas, para a 
escola, as novas exigências que lhe são impostas desestabilizaram a profissão docente; o sentimento de desprofissionalização está vivo.

Mais recentemente, as políticas mostram-se muito sensíveis às ações de lobbies promovidas pela neurociência e pelo mundo digital como soluções a todos os problemas educativos. Isso manifesta o retorno a um positivismo, ignorando a complexidade da educação como um "fato social total" (MAUSS) e uma visão dessocializada e instrumental da educação que visa à empregabilidade acima de tudo. 0 sistema educativo francês é conhecido (após as pesquisas internacionais, como o Programme for International Student Assessment - PISA) por ser um sistema muito desigual. A reprodução social apontada por Pierre Bourdieu é ainda atual. 0 antigo modelo de profissionalidade dos professores não é mais adaptado; ele foi promovido por certas políticas públicas que procuravam formar engenheiros pedagógicos ou executadores de normas pensadas por outros e que não encontram consenso e, ademais, entram em conflito com a história da profissão e com um conjunto de seus compromissos e missões.

Os professores são igualmente pressionados entre expectativas sociopolíticas que, por vezes, são contraditórias: ser benevolente, garantir o florescimento das crianças, fazer com que todos os alunos sejam bem-sucedidos e, ao mesmo tempo, assegurar a seleção de uma elite, orientar os mais fracos em direção às plataformas de formação que são plataformas de relegação, ao preço de uma violência institucional e de certas discriminações sociais, étnicas. Os professores são, assim, obrigados a fazer uma arbitragem entre princípios, lógicas de ação, gestos profissionais diferentes, o que causa, inevitavelmente, tensões em suas atividades.

\section{Qual é o papel desses assuntos sensiveis nessas transformações profissionais?}

Os assuntos sensíveis são os conteúdos de ensino que provocam debate tanto no plano acadêmico como no político ou didático. Eles são diretamente ligados ao debate público e científico que penetram nas salas de aula. Eles variam segundo os períodos. 0 ensino de história das cruzadas não era um assunto sensível, mas se tornou, o que exigiu uma reflexão epistemológica e uma formação contínua aprofundada dos professores, dois pontos fracos atualmente. Os assuntos sensíveis são reveladores da fabricação do currículo (das lutas entre diferentes grupos e diversas concepções), da maneira de sustentar as situações em sala de aula e de justificar as escolhas pedagógicas e didáticas.

Para tratar desses assuntos, seria preciso grupos de trabalho na direção de uma reflexão coletiva sobre como fazer, uma vez que a intensificação do trabalho dos professores, as modalidades de avaliação que os colocam em concorrência e as organizações de trabalhos inadaptadas contrariam a necessidade do coletivo. Assim, a sobrecarga de trabalho, o sentimento ocasional de incompetência, a pressão para resultados e a falta de reconhecimento pela hierarquia são a origem de um descomprometimento (foi constatado um aumento de demissões de jovens professores), do sofrimento no trabalho, do esgotamento profissional.

Uma pesquisa recente, que eu orientei, acerca dos professores em fim de carreira bastante insatisfeitos com seu trabalho mostra que o sentimento de satisfação dos professores é ligado, notadamente, a duas dimensões: à autonomia preservada e ao 
pensamento crítico com relação às próprias práticas e às prescrições. Contrariamente ao senso comum, os docentes não buscam somente o conforto pelo abrandamento da carga de trabalho, mas a possibilidade de definir e escolher para si os desafios que relançam seu interesse pela profissão. Essa pesquisa enfatizou também que os professores em fim de carreira que estão satisfeitos constroem fontes de reconhecimento de seu trabalho no exterior da instituição, o que compensa a insuficiência institucional. As questões vivas estimulam esses fenômenos quando elas não são ocultadas pelos professores.

Como se dá a exigência de neutralidade dos professores com relação a essas questões sensíveis?

A exigência de neutralidade feita aos professores entra em tensão com a missão que o Estado lhes dá de educar para valores da República, missão reforçada desde os atentados de 2015. Efetivamente, educar para valores da República implica que os professores não sejam... neutros. Eles devem, então, diferenciar o respeito da liberdade de consciência dos alunos e de seus pais, se concentrar nos saberes acadêmicos, assumir a parte normativa da instituição escolar sem deixar de lado a neutralidade requisitada a respeito de suas próprias opiniões e valores e, ainda, formar os alunos para que eles tenham um pensamento crítico. Não é simples.

Na sua opinião, quais são os pontos positivos e os pontos negativos da exigência de uma especialização (mestrado) para os professores na França?

0 ponto positivo é, além da uniformização europeia que garante a mobilidade, o aumento do nível de qualificação dos professores, sendo um ponto de apoio para o seu trabalho e seu status social. 0 ponto negativo é, sobretudo, o prolongamento dos estudos; a falta considerável de ajuda e de uma adaptação à formação têm distanciado os jovens provenientes do meio popular. 0 trabalho docente torna-se, mais do que antes, um trabalho feminizado e de camada média, uma profissão escolhida à revelia (sobretudo pelos rapazes vindos de setores científicos) pois, no mesmo nível de qualificação, algumas formações permitem acessar empregos mais bem remunerados, menos árduos e mais valorizados. Essa é uma das causas da crise de recrutamento que a escola francesa conhece sobretudo nas disciplinas científicas para o secundário (Ensino Fundamental II e Ensino Médio) e, em certas regiões e bairros menos atrativos, para o primário (Ensino Fundamental I). Ademais, a ausência de uma real revalorização salarial, apesar da elevação do nível de qualificação, impediu os efeitos previstos em termos de reconhecimento social, o que tem causado o ressentimento de certos professores novatos que, após longos estudos, um concurso difícil e uma formação profissional inicial desigual são confrontados com uma carga de trabalho e um nível de responsabilidade elevados, com uma condição cotidiana penosa e depreciada. No entanto, o acompanhamento durante dois anos de uma coorte de estudantes que foram aprovados no concurso para o primário mostra que eles são mais autônomos e sabem, melhor que seus colegas experientes, encontrar os recursos para resolver os problemas 
encontrados sem esperar um posicionamento da hierarquia, tornando a atitude que eles possuem com relação à hierarquia mais distanciada que anteriormente. Sua formação traz, por vezes, recursos para seus colegas mais experientes, sobre alguns assuntos, por exemplo, como a educação especial, por conta da formação obtida durante o mestrado.

Na sua opinião, como se constrói a abordagem entre o pesquisador e o professor na escola francesa?

Existem diferentes formas de construí-la. De minha parte, a temporalidade é um elemento chave. Compartilhar o cotidiano de uma escola ou de um estabelecimento secundário, construir relações de confiança com os professores é decisivo para acessar as dimensões de sua atividade que não são prescritas, que são por vezes clandestinas e, assim, não conhecidas e reconhecidas. A postura não pode ser de um especialista, mas de modéstia, de alguém que procura compreender o enigma do trabalho, com a contribuição dos professores. Além disso, graças ao Instituto francês de educação ${ }^{5}$ (IFE) ligado à Escola normal superior de Lyon 6 , eu convido professores para se associar (de outras escolas ou estabelecimentos do secundário que não fazem parte do campo da pesquisa) ao projeto de pesquisa desde sua concepção até a valorização dos resultados. Eles trazem uma contribuição importante à pesquisa pelo seu conhecimento interno do trabalho e, ao mesmo tempo, se formam nos métodos de pesquisa e se beneficiam das trocas com os pesquisadores universitários. Isso constitui um tipo de triângulo (professores do campo de pesquisa, professores associados ao grupo de pesquisa, pesquisadores experientes e novatos, doutorandos), que cria uma dinâmica favorável, com a pluridisciplinaridade.

Como é o engajamento do professor nas pesquisas acadêmicas na França? Eles compartilham suas experiências reais com os pesquisadores? Existe um diálogo entre vocês quando a pesquisa chega ao fim?

0 engajamento do professor nas pesquisas é raro. Eles são mais frequentemente objetos de pesquisa do que colaboradores. 0 trabalho coletivo com os pesquisadores não é fácil, precisa de tempo para que cada um possa identificar sua contribuição, os pontos possíveis de debate e para adquirir ousadia para, eventualmente, discordar e propor controvérsias. A organização regular de seminários abertos, a eventual contribuição de pesquisadores exteriores e o compartilhamento da experiência de pesquisa contribuem para constituir um coletivo de pesquisa com os professores associados. Isso é possível também na medida em que a instituição, que subvenciona o IFE, concede uma ajuda de custo aos professores associados, o que assegura um reconhecimento mínimo de seu trabalho. Mas as diferenças permanecem, pois para os pesquisadores universitários, existem exigências de publicações acadêmicas, por exemplo, que não é o caso dos professores associados. Também porque, para alguns, a pesquisa é profissão, enquanto que para os outros é, sobretudo, um meio de formação continuada, de desenvolvimento profissional.

5- Institut Français D'Éducation (IFE).

6- Ecole Normale Supérieure de Lyon. 
Ao fim da pesquisa ou de certas etapas, nós organizamos uma jornada de estudo, um colóquio, em que os professores associados que desejam podem fazer uma comunicação sobre o trabalho. Nós os acompanhamos na preparação de suas comunicações. Com frequência, alguns professores associados que participam das publicações (artigos, obras) retomam os estudos em um curso de formação ou desenvolvem uma tese. Segundo os professores que participaram de uma ou várias pesquisas, a experiência é um enriquecimento intelectual e isso os direciona para fazer evoluir suas práticas profissionais. Após a pesquisa, nós fazemos um trabalho de valorização para além da esfera acadêmica, o que nos permite apresentar os resultados de nossas pesquisas aos professores e discutir, eventualmente, com eles. A divulgação dos resultados aos sindicatos é um meio para alcançar os professores, pois eles são também afetados pelas evoluções do trabalho dos professores e interessados em compreendê-lo melhor.

\section{Referências citadas pela entrevistada}

BOLTANSKI, LUC; THÉVENOT, Laurent. De la justifcation: les économies de la grandeur. Paris: Gallimard, 1991.

DUBAR, Claude. A socialização: construção das identidades sociais e profissionais. Tradução Andréa Stahel M. da Silva. São Paulo: Martins Fontes, 2005.

LANTHEAUME, Françoise (Dir.); BESSETTE-HOLLANDE Francoise; COSTE, Sabine (Col.). Les enseignants de lycée professionnel face aux reformes: tensions et ajustements dans le travail. Lyon: INRP, 2008.

LANTHEAUME, Françoise; HÉLOU, Christophe. La souffrance des enseignants: une sociologie pragmatique du travaill enseignant. Paris: PUF, 2008.

LANTHEAUME, Françoise; LÉTOURNEAU, Jocelyn (Dir.). Le récit du commun: I'histoire nationale racontée par les élèves. Lyon: PUL, 2016.

\section{Outras publicações de Françoise Lantheaume}

LANTHEAUME, Françoise. Dimensions cachées du travail: ressource et obstacle face aux épreuves de la sur-prescription: exemple de professionnels de l'éducation. In: CHAMPY-REMOUSSENARD, Patricia. En quête du travail caché: enjeux scientifiques, sociaux, pédagogiques. Toulouse: Octares, 2014. p. 53-66.

LANTHEAUME, Françoise. Entre sclérose et plasticité professionnelle: se développer tout au long de sa carrière. In: RIA, LUC; BORER, Lussi V. Apprendre à enseigner. Paris: PUF, 2015. p. 181-191.

LANTHEAUME, Françoise. Fait colonial et religion dans les programmes et les manuels scolaires In: BORNE; Dominique; FALAIZE, Benoit. Religion et colonisation. Paris: L'Atelier, 2009. p. 256-262.

LANTHEAUME, Françoise. La professionnalité des enseignants à l'épreuve de la durée les ressources de la plasticité professionnelle. In: RIA, LuC (Coord.) Former les enseignants au XXle siècle: professionnalité des enseignants et de leurs formateurs. v. 2. Bruxelles: De Boeck, 2016. p. 67-75.

LANTHEAUME, Françoise. Le récit de l'histoire de France par la jeunesse scolarisée: références communes, ruptures culturelles. Á l'école de Clio, Dossier n. 1, 2015. Récits et mises en texte du passé. Disponível em: <http://ecoleclio.hypotheses.org/201. 2015>. Acesso em: 29 jul. 2018. 
LANTHEAUME, Françoise. Les religions à l'école: pureté des principes, hybridation des pratiques? Histoire, Monde et Cultures Religieuses, Paris, v. 4, n. 32, p. 9-13, 2014.

LANTHEAUME, Françoise. L'activité enseignante entre prescription et réel: ruses, petits bonheurs, souffrance. Éducation et Sociétés, Paris, v. 19, n. 1, p. 67-81, 2007. Disponível em: <http://www.cairn. info/revue-education-et-societes-2007-1-page-67.htm. 2007>. Acesso em: 29 jul. 2018.

LANTHEAUME, Françoise. L'empire dans l'enseignement de l'histoire en France: de la promesse au fardeau. In: FALAIZE, Benoit; HEIMBERG, Charles; LOUBES, Oliver (Dir.). L'école et la nation. Lyon: ENSL, 2013. p. 427-434.

LANTHEAUME, Francoise. L'enseignement du fait colonial entre universalisme républicain et mémoires singulières. In: LAURENCE, De Cock (Dir.). La fabrique de I'histoire scolaire. Marseille: Agone, 2017. p. 73-86.

LANTHEAUME, Françoise. Professores e dificuldades do ofício: preservacão e reconstrução da dignidade profissional. Cadernos de Pesquisa, São Paulo, v. 42, n. 146, p. 370-389, maio/ago. 2012.

LANTHEAUME, Françoise. Recherche en éducation, action publique éducative et transformation du métier d'enseignant: la tentation du grand ménage et du couteau suisse. In: PIOT, Thierry; MARCEL; Jean-François (Dir.). Changements en éducation Intentions politiques et travail enseignant. Toulouse: Octares. 2017. Chap. 1.

LANTHEAUME, Francoise. Souffrances professionnelles. In: JORRO, Anne. Dictionnaire des concepts de la professionnalisation. Bruxelles: De Boeck, 2014. p. 301-304.

LANTHEAUME, Françoise. The empire in French history teaching: from a promise to a Burden. In: CARRIER, Peter (Ed.). School and nation: identity politics and educational media in an age of diversity. Frankfurt am Main: Peter Lang, 2013. p. 15-23.

LANTHEAUME, Francoise; HÈLOU, Christophe. Violence à l'école et souffrance au travail des enseignants: l'échec du travail d'inntéressement et les loupés de l'organisation du travail? La Matière et L'Esprit, $p$. 25-47, nov. 2005: Número spécial: Violences à l'école. Neuf approches qualitatives, Université de MonsHainaut. 